\title{
Effects of Service Quality on Customers Satisfaction on Botswana's Mobile Telecommunications Industry
}

\author{
Gorata Bessie Selelo \\ Botswana Competition Authority, Gaborone, Botswana
}

\author{
Khaufelo Raymond Lekobane \\ Botswana Institute for Development Policy Analysis (BIDPA), Gaborone, Botswana
}

\begin{abstract}
Botswana's telecommunications sector has shown significant growth over the years. This is evidenced by the increase in the number of mobile operators, coupled with a drastic increase in the number of consumers. Notwithstanding this, the mobile sector is challenged to continually find ways to ascertain that their products and services meet customers' expectations, in order to provide improved quality of service and ensure customer satisfaction. This study therefore, examines the relationship between service quality and customer satisfaction in the mobile sector and compares levels as well as analyse the determinants of service quality. The SERVQUAL model was adopted for this study, through which twelve dimensions of service quality were explored and measured. Principal component analysis was employed to compute the customer satisfaction and service quality indices. The regression results showed that, across all mobile operators; Assurance, Credibility, Security and Tangibles are the major dimensions that are significantly and positively related to customer satisfaction. Therefore, service providers need to focus on issues of assurance, credibility, security and tangibles among others, to increase satisfaction levels among their customers.
\end{abstract}

Keywords: Botswana; telecommunications; service quality; customer satisfaction; principal component analysis; ordinary least squares.

\section{INTRODUCTION}

The telecommunications industry is very important in the development of the economy, as it ensures ease of service provision and facilitates business transactions. At a macroeconomic level, good telecommunications infrastructure has been shown to have a positive relationship to economic growth (Sridhar \& Sridhar, 2009). It is in this light that Botswana's telecommunications sector has shown significant growth over the years. This is evidenced by the increase in the number of mobile operators from zero in the 1990s to currently three mobile service operators. These Public Telecommunication Operators (PTOs) are Mascom, Orange (formerly Vista) and BeMobile (a subsidiary of Botswana Telecommunications Corporation). Mascom and Orange both started operations in 1998 while BeMobile followed a decade later in 2008. The three PTOs provide local, national and international mobile services. In addition, Botswana's telecommunications industry continues to show significant growth with respect to the total number of consumers of the services provided by the mobile service operators. The numbers of consumers have increased more than 30 times from 106,029 in 2000 to 3,410,507 in 2014 (Statistics Botswana, 2016).

The sector is regulated by the Botswana Communications Regulatory Authority (BOCRA), which has the prerogative to license operators, as per the Communications Regulatory Authority Act of 2012 and guidelines established by the 1995 Telecommunication Policy. Analysys Mason (2009) carried out a market study (as commissioned by BOCRA, the then 
Botswana Telecommunications Authority); and the results of the study showed that Botswana's mobile telephone industry was performing quite well. This was evidenced by strong penetration and coverage levels (at around 80 percent), which compared well to best practice countries such as South Africa and Namibia (at about 80 and 50 percent, respectively). Also, there was an indication that the country was still expected to experience more growth in the mobile prepaid market due to the high incidence of multiple subscriptions. The review concluded by pointing out that there was indeed effective competition in this sector.

It is imperative that those managing the PTOs be aware of how to ensure that they meet (or even exceed) customer expectations. This is because a high quality of service is one major aspect of retaining or increasing one's market share. The mobile telephone sector is challenged to continually find ways to ascertain that their products and services meet customers' expectations. Customer satisfaction is crucial for a company's long term business success. In order to retain or gain more market share, service providers ought to outperform their competitors through offering high quality products/service, to ensure clients are satisfied (Saghier \& Nathan, 2013). The PTOs can ensure customer satisfaction only if they have knowledge of the extent of customer sensitivity and expectation towards the services they offer. Therefore, the objective of this study was to assess the level of customer satisfaction and make a comparative analysis of the effect of service delivery on customer satisfaction in Botswana's mobile telecommunications sector. This particular study augmented on the already limited literature on Botswana's telecommunications sector in that it looked into the effect service quality has on customer satisfaction, from the customer's view point. This helped bridge the gap left by previous studies (such as Analysys Mason, 2009), which only focused on mobile network penetration and other developments in the sector at a macro level.

\section{LITERATURE REVIEW}

Service quality is usually defined in various ways, depending on the situation being assessed as well as the factors of interest. It is usually explained as customer sensitivity to the extent to which a service adequately meets or exceeds expectations (Czepiel, 1990). Literature on service marketing generally defines service quality as the overall evaluation of the service offered. This assessment is done by customers on the receiving end (Eshgi et. al., 2008). Parasuraman et al. (1985) describes service quality as “The discrepancy between consumers' perceptions of services offered by a particular firm and their expectations about firms offering such services" (pp. 49). Therefore, the consumer would judge a low quality service as service that is below expectation and vice-versa. A crucial component of service quality is the customer's expectation (what they feel the service provider should offer), which is influenced by personal needs; previous experience; other customers' referrals and the provider's communication strategy (Parasuraman et al., 1985).

Literature highlights that it is quite a challenge to measure service quality due to its intangibility nature, which is difficult to quantify. Intangibility refers to the lack of a physical product to; touch, taste, smell or hear, before any purchases are made, which makes it difficult for the consumer to understand the nature of what they actually receive (Daniel \& Berinyuy, 2010). For instance, in the case of a company offering mobile telecommunication services; here the consumer just makes calls and does not receive any physical/tangible product. This therefore requires service providers to make efforts to determine the level of intangibility of services and try to incorporate tangible elements that could help better understand expectations from the consumer's perspective.

Most research shows that service quality is a major determinant of customer satisfaction and retention. Ahmed et al. (2010) assessed the impact of service quality on customer satisfaction in Pakistani telecommunication sector and found that the service quality measures of; 
tangibles, assurance, responsiveness, reliability and empathy had a positive and significant relationship with customer satisfaction. Similarly, Loke et al. (2011), using the service quality scale (SERVQUAL) model, looked at the impact of; reliability, responsiveness, assurance, empathy and tangible aspects on customer satisfaction in Malaysia's telecommunications sector. Results highlighted that though all five dimensions explained more than 80 percent of the customer satisfaction; empathy, reliability and responsiveness showed the strongest and significant effect on customer satisfaction and loyalty.

Joshi et al. (2010) assessed service quality in India's telecommunication sector, focusing primarily on three service providers in three localities (Chandigarh, Panchkula and Mohali) and highlighted seven dimensions of quality to be assurance, reliability, tangibles, responsiveness, empathy, network quality, and any other factor. Of these seven, results showed that, five of them (empathy, assurance, responsiveness, network quality and any other factors) had a significant influence on the customers' perceptions of service quality. Agyapong (2011) conducted a study on the effect of service quality on customer satisfaction in the Vodafone telecomm company (Ghana). The study used a modified service quality scale (SERVQUAL model) for analyzing service quality. Multiple regression analysis was used to examine the relationship between service quality variables (tangibles, reliability, responsiveness, competence, courtesy, feeling secure, communication and customer understanding) and customer satisfaction. The results showed that all the service quality variables were good predictors of customer satisfaction, and that, if no action is taken to enhance these variables' levels, customer satisfaction would decline.

\section{METHODOLOGY}

There are a number of perspectives used when looking into customer satisfaction. Evaluation of customer satisfaction is typically with respect to both technical and functional qualities. However, because customers rarely have the technical expertise to evaluate services offered, functional quality plays a major role in forming a basis for service quality (Agyapong, 2011). There are a number of models and tools used to measure customer satisfaction. ${ }^{1}$ The SERVQUAL (Service Quality model) is the most widely used model, since it identifies gaps between customers' expectations from an excellent service provider, to their perception on service offered by their current service provider (Szwarc, 2005). This model was developed by Parasuraman et al. (1985), based on the fact that, in order to maintain satisfied customers, one ought to ensure that customers' perception on service offered is not that far off from their expectations. Various dimensions of service quality are looked into here, and among others; tangibles, reliability, responsiveness, assurance and empathy. The strength of the model is that it is applicable in various industries and sectors. This study adopted the SERVQUAL model (Parasuraman et al, 1985), which is in line with similar studies on service quality (Agyapong, 2011; Loke et al., 2011). Twelve dimensions of service quality were explored and measured. Table 1 presents the variables (dimensions) and their descriptions/definitions. The conceptual framework for the study was adopted and modified from empirical studies on service quality and customer satisfaction (Agyapong, 2011; Dehghan, 2006; Parasuraman et al., 1985). The framework indicates that service quality is a predecessor of customer satisfaction.

${ }^{1}$ Other models include Simalto and Conversion models 
The study surveyed a total of 510 mobile telephone users, randomly selected around Gaborone, across the three mobile operators. The sample size was determined using the Cochran (1977) formula. The probability proportional to measure of size approach was used to allocate the sample across the three mobile operators; with the operator with the highest number of subscriptions taking the larger share. To determine the effect of service quality on customer satisfaction, which was the main objective of the paper, customer satisfaction (dependent variable) was regressed against the twelve service quality dimensions. The twelve dimensions of service quality used in the study were adopted from Parasuraman et al. (1985; 1988). The ordinary least square estimation technique was employed following Agyapong (2011) as follows;

$$
Q=\alpha+\sum_{i=1}^{n} \beta_{i} X_{i}+\varepsilon_{i}
$$

where, $Q$ measures customer satisfaction, $X_{i}^{\prime}$ s are the service quality dimensions, $\beta_{i}$ denote the coefficients to be estimated, $\alpha$ is the intercept term and $\varepsilon_{\mathrm{i}}$ is the error term. Principal component analysis (PCA) technique was also employed in the analysis of the data. PCA is a multivariate technique used to reduce the number of variables in a data set into a smaller number of dimensions (Vyas and Kumaranayake, 2006). In mathematical terms, from the initial set of $n$ correlated variables, PCA creates uncorrelated indices or components, where each component is a linear weighted combination of the initial variables. For example, from a set of $X_{1}$ through $X n$,

$$
\begin{gathered}
P C_{1}=a_{11} X_{1}+a_{12} X_{2}+\cdots+a_{1 n} X_{n} \\
\vdots \\
P C_{m}=a_{m 1} X_{m}+a_{m 2} X_{2}+\cdots+a_{m n} X_{n}
\end{gathered}
$$

where, $a_{m n}$ represents the weight for the $m$ th principal component and the $n$th variable.

The weights for each principal component are given by the eigen vectors of the correlation matrix. The variance $(\lambda)$ for each principal component is given by the eigenvalue of the corresponding eigenvector. The components are ordered so that the first component $\left(\mathrm{PC}_{1}\right)$ explains the largest possible amount of variation in the original data, subject to the constraint that the sum of the squared weights $\left(a_{11}^{2}+a_{12}^{2}+\cdots+a_{1 n}^{2}\right)$ is equal to one (Vyas and Kumaranayake, 2006). As the sum of the eigenvalues equals the number of variables in the initial dataset, the proportion of the total variation in the original data set accounted by each principal component is given by $\lambda_{i} / n$. The second principal component $\left(\mathrm{PC}_{2}\right)$ is completely uncorrelated with the first component, and explains additional but less variation than the first component, subject to the same constraint. Subsequent components are uncorrelated with previous components; therefore each component captures an additional dimension in the data, while explaining smaller proportions of the variation of the original variables. 
Table 1: Variable Description

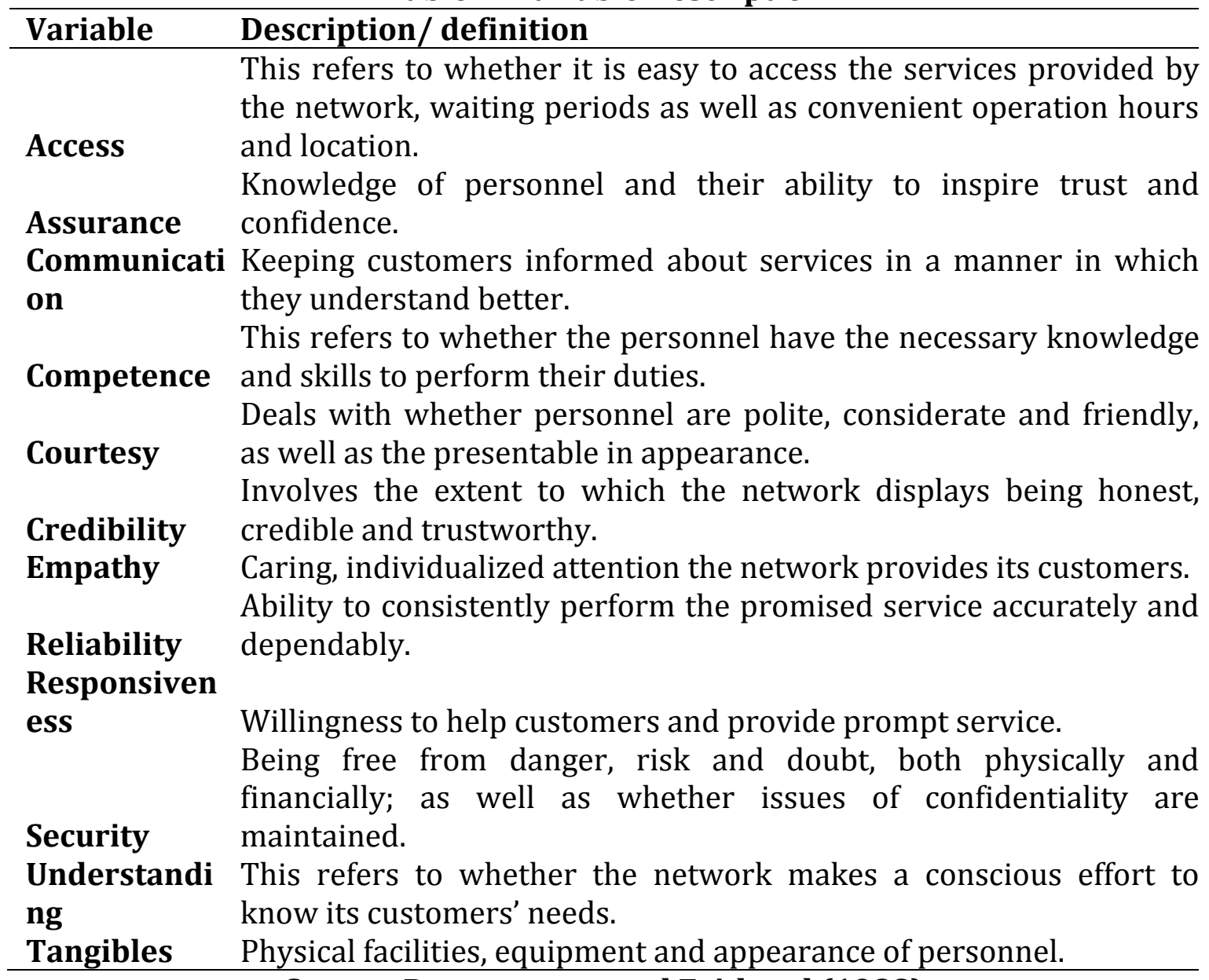

Source: Parasuraman and Zeithaml (1988)

\section{Descriptive Analysis of the Results}

\section{RESULTS AND DISCUSSIONS}

This section gives a narrative of the results of the analysis carried out, on the effect of service quality on customer satisfaction in the mobile telecommunications sector. Table A1 of the appendices shows the descriptive statistics of variables for the service quality measure. Respondents had to rate the level of importance they attributed to each service quality variable, for the particular mobile operator they affiliate with. Table A1 shows the average responses for all the mobile operators. Across all three mobile operators, the most important dimensions of service quality were shown to be; communication and courtesy at a mean score of 4.2. That is, for customers to deem an operator to provide a quality service there is need to communicate with customers through regular updates and promptly respond to their queries. Also, customers require operators to be polite, patient and sincere when assisting them (courtesy). The average rating of 3.8 for the tangibles dimension was the lowest across all networks, indicating that customers do not place a very high importance on the appearance of office space, staff and equipment used, as compared to other dimensions of service quality.

The descriptive statistics on Table A2 shows the respondents' perception on how their choice of mobile operator's service quality meets their expectations. The responses are on a scale of 15 (i.e. 1- much worse than expected, 2- worse than expected, 3- equal to my expectation, 4- 
better than expected and 5- much better than expected). Across all mobile operators, customers felt that the mobile operators' level of courtesy when assisting clients was better than expected, with an average score of 3.8. This dimension still remained dominant when the responses were split according to the mobile operators, as customers from each of the three operators showed the highest rating for courtesy. When looking at the least scored variable for customers across all operators, waiting period had a consistent average score of 3.3 across the board. This indicated that the average waiting period experienced by the customers is as per expectation. In terms of overall satisfaction ratings across all mobile operators, the results of the survey showed that majority of the respondents, at 66.9 percent, were either satisfied or very satisfied with their network provider. About a quarter (25.9 percent) of the respondents indicated that they were neither satisfied nor dissatisfied with their mobile operator. Though this was not necessarily negative feedback, more could be done to unpack this apparent indecisiveness and work towards improving it to a "satisfied" rating.

Table A3 highlights the percentage variations as explained by the eigenvalues for each of the dimensions assessed, on the perceived level of service quality. The cumulative column in the table shows that 52.3 percent of the variations in the perceived service quality are due to issues of access (ease of access, waiting period and convenience). The eigenvalues of at least 1 provide insight on how many principal components to extract in our analysis. Therefore, based on Table A3, there are only three variables (pertaining to access) with eigenvalues above 1 , indicating that our analysis will extract 3 principal components. Similarly, from Table A4, we obtain the percentage variations as explained by the eigenvalue for each of the dimensions assessed, on how the mobile operator's service quality meets customers' expectations. The cumulative column in the table shows that 62.7 percent of the variations in the perceived service quality are due to issues of access (ease of access, waiting period and convenience) and assurance (value added services and confidence). These two dimensions, (access and assurance), have the highest eigenvalues as indicated in Table A4 (figures bolded in the table). Based on the eigenvalues of at least 1 rule, Table A4 therefore shows that our analysis should extract 4 principal components.

A determination of the correlation between the principal components and the 12 dimensions of service quality in the study was carried out, as shown in Figure 1 and Table A5, in relation to the customer perceptions of service quality. Three principal components were extracted in our analysis, and due to standardization, they all had a zero mean. In determining the correlation, we looked at variables with the strongest correlation with component 1 , as shown by the large magnitude, the farthest from zero in either a positive or negative direction. For the purposes of this analysis, our correlation value which indicated importance is at least 0.29 (figures bolded in Table A5). Component 1 was shown to be strongly correlated to six dimensions. The component increased with an increase in the mobile operator's; communication, courtesy, credibility, empathy, reliability and responsiveness. This suggested that these six dimensions vary together. If one increases, then the remaining ones also increase. 


\section{Figure 1: Correlation of Customer Perception on Service Quality}

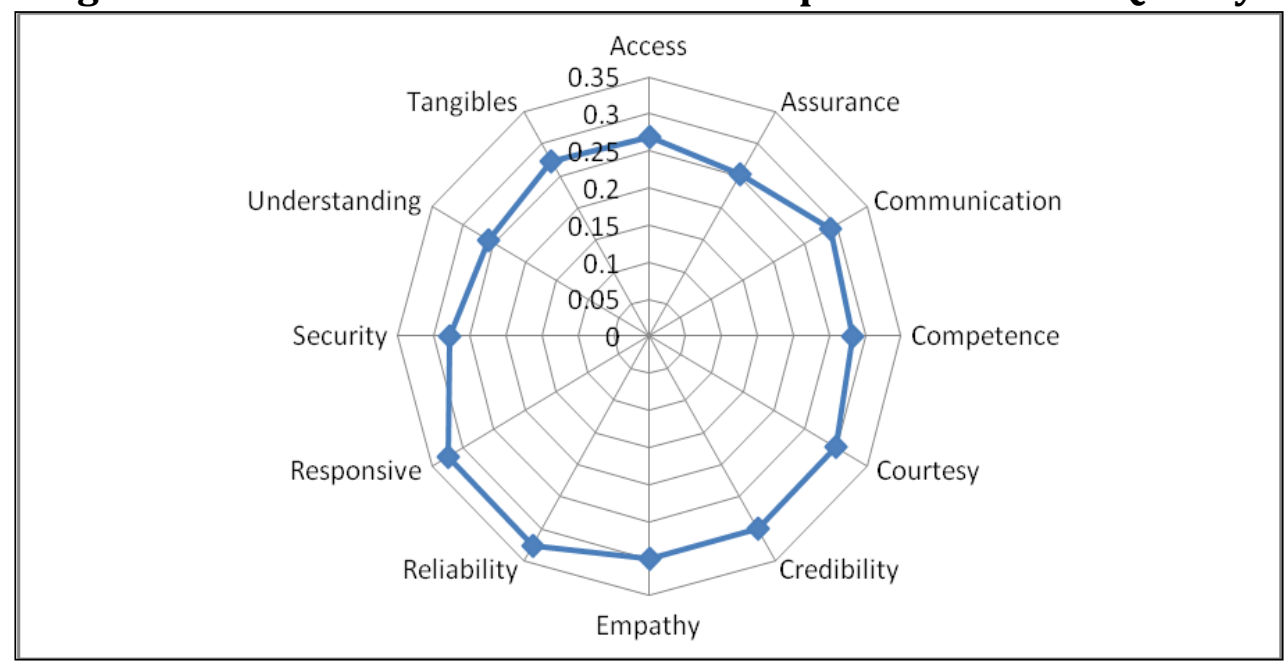

Source: Author computed from survey data (2014)

Figure 2 and Table A6 highlight the correlation between component 1 and the 12 dimensions of service quality, with respect to customer expectations. Component 1 showed a stronger correlation to three dimensions (communication, reliability and responsiveness). These indicated that the component increased with each of the dimensions. These results are consistent across customer expectation and service quality with regard to reliability and responsiveness dimensions. However, with regard to service quality, communication dimension showed a stronger correlation with component 1, whilst for customer expectation, credibility showed a stronger correlation with component 1.

Figure 2: Correlation of Customer Expectations

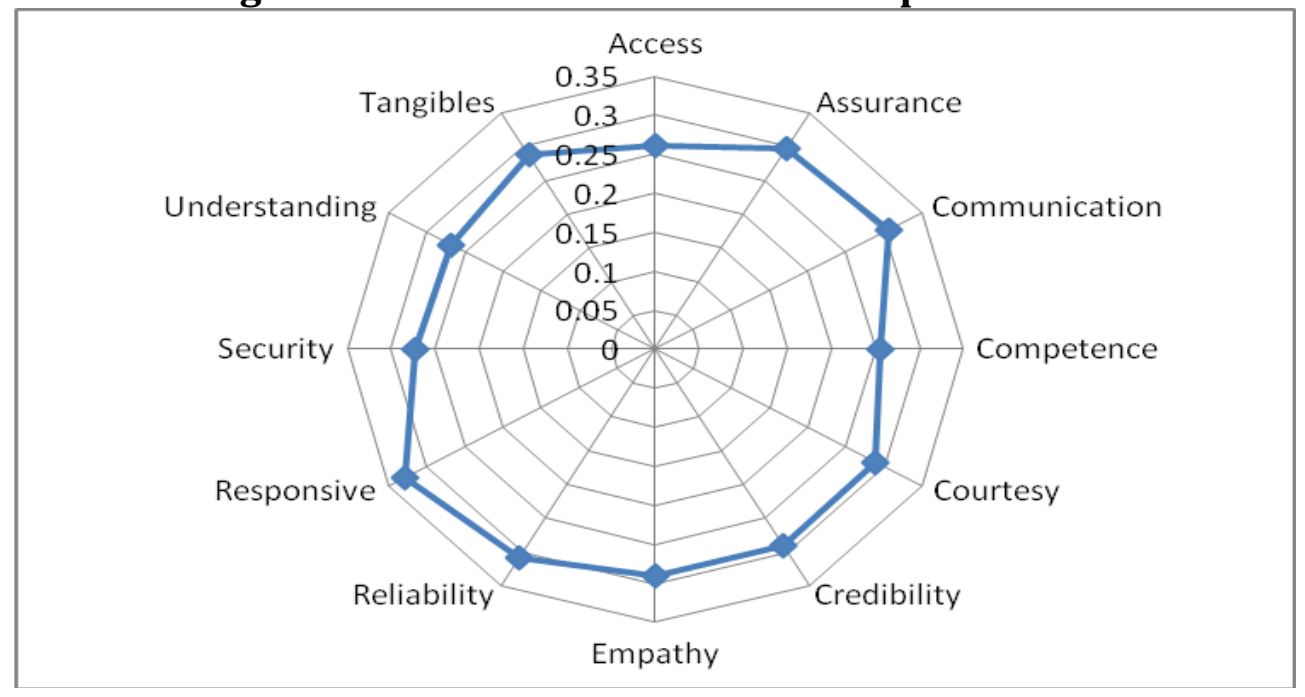

Source: Author computed from survey data (2014)

On average, customers across all mobile operators gave a score of 3.59, indicating that the level of service quality by the mobile industry was a little over their expectations. The scores when split according to the mobile operator indicated a slight difference between the scores of the 3 operators' subscribers. These scores ranged from 3.56 to 3.64 with a difference of between 0.04 and 0.08 . Table A6 shows the gaps between perceived service quality and customers' 
expectations. The dimension with the largest gap was Credibility (importance score 4.07 and expectation score 3.54). The top five dimensions, with a gap ranging from 0.44 to 0.53 , were; Credibility, Access, Responsiveness, Competence and Courtesy. These values were all positive, a clear indication that the level of service quality perceived by the customers was more than expected.

\section{DETERMINANTS OF SERVICE QUALITY ON CUSTOMER SATISFACTION}

Table 2 presents regression results for the service customer satisfaction models. We report the results for the overall model, where the independent variables account for about 19 percent of the total variation in the dependent variables. The F-statistic is highly significant $(\mathrm{p}<0.001)$, implying that the explanatory variables jointly exert significant influence on customer satisfaction.

Table 2: Determinants of Customer Satisfaction

\begin{tabular}{|c|c|c|c|c|}
\hline Variables & Coefficient & $S E$ & $t$ & $P>t$ \\
\hline Access & -0.14 & 0.21 & -0.66 & 0.509 \\
\hline Assurance & 0.41 & 0.19 & 2.16 & $0.031^{* *}$ \\
\hline \multicolumn{5}{|l|}{ Communicatio } \\
\hline $\mathrm{n}$ & -0.03 & 0.22 & -0.12 & 0.907 \\
\hline Competence & -0.09 & 0.17 & -0.51 & 0.607 \\
\hline Courtesy & 0.14 & 0.21 & 0.67 & 0.504 \\
\hline Credibility & 0.32 & 0.19 & 1.66 & $0.098^{*}$ \\
\hline Empathy & -0.09 & 0.20 & -0.44 & 0.658 \\
\hline Reliability & 0.31 & 0.26 & 1.20 & 0.230 \\
\hline \multicolumn{5}{|l|}{ Responsivenes } \\
\hline $\mathrm{s}$ & -0.04 & 0.26 & -0.17 & 0.866 \\
\hline Security & 0.34 & 0.17 & 1.98 & $0.048^{* *}$ \\
\hline Understanding & 0.18 & 0.18 & 0.99 & 0.322 \\
\hline Tangibles & 0.90 & 0.21 & 4.21 & $0.000^{* * *}$ \\
\hline Constant & -8.71 & 0.84 & -10.34 & $0.000 * * *$ \\
\hline $\begin{array}{l}\text { No. of } \\
\text { observations }\end{array}$ & 510 & & & \\
\hline F-Statistics & 11.11 & & & $0.000^{* * *}$ \\
\hline Adjusted R ${ }^{2}$ & 0.19 & & & \\
\hline
\end{tabular}

Source: Author computed from survey data (2014) ${ }^{*, * *}$, and ${ }^{* * *}$ significant at 10,5 and 1 percent, respectively.

The overall model showed that, all the significant variables carry the expected signs. Across all operators; assurance, credibility, security and tangibles are the four variables shown to be the major determinants of customer satisfaction. Assurance positively relates with customer satisfaction, an indication that customers' knowledge of personnel and their ability to inspire trust and confidence positively relate with the customers' satisfaction level. The results are consistent with previous studies conducted in other countries, such as Agyapong (2011), which showed that the extent to which a mobile operator demonstrates a level of honesty and trustworthiness is of importance to customers in the mobile telecommunications sector, as demonstrated by the positive impact credibility has on customer satisfaction. Security positively relates to customer satisfaction, an indication that, customer satisfaction improves with the degree at which the mobile operator is perceived to maintain confidentiality and be less risky. Also, the positive relationship between tangibles and customer satisfaction shows that customers are very much concerned with the appearance of an operator's facilities, equipment and personnel. 


\section{SUMMARY AND CONCLUSIONS}

Botswana's telecommunications sector has shown significant growth over the years as evidenced by the increase in the number of mobile operators and by the total number of consumers of mobile service providers. Mobile operators grew from zero to the current three, and the number of consumers increased from about 106,000 in 2000 to 3.4million in 2014. The objective of this study was to assess the level of satisfaction and make a comparative analysis of the effect of service delivery on customer satisfaction in Botswana's mobile telecommunications sector. The specific objectives of this study were to determine the relationship between service quality and customer satisfaction in the mobile sector and compare levels and determinants of service quality between operators. The study surveyed a total of 510 customers, randomly selected across all three mobile operators around Gaborone.

The results of the study confirmed that indeed there exists a strong relationship between service quality and customer satisfaction in Botswana's telecommunications sector. Across the three networks, the most important dimensions of service quality were shown to be communication and courtesy. That is, for customers to deem an operator to provide a quality service there is need to communicate with customers through regular updates and promptly respond to their queries. Also, customers require operators to be polite, patient and sincere when assisting them (courtesy). The average rating of the tangibles dimension was the lowest across all operators, indicating that customers do not place a very high importance on the appearance of office space, staff and equipment used, as compared to other dimensions of service quality.

The results of the survey also showed that overall satisfaction ratings across all mobile operators indicated that majority of the respondents, were satisfied with their network provider and the results were consistent across the three mobile operators. On average, customers across all operators gave a score of 3.6, indicating that the level of service quality by the mobile industry were a little over their expectations. With regard to the gaps between perceived service quality and customers" expectations, the top five dimensions, with wider gaps were; Credibility, Access, Responsiveness, Competence and Courtesy, with gaps ranging from 0.44 to 0.53 , a clear indication that the level of service quality perceived by the customers is more than expected. The regression results showed that, across all mobile operators; assurance, credibility, security and tangibles are the major dimensions that are significantly and positively related to customer satisfaction. Therefore, service providers need to focus on issues of assurance, credibility, security and tangibles among others to increase satisfaction levels among their customers.

\section{References}

Agyapong, G.K. (2011). The Effect of Service Quality on Customer Satisfaction in the Utility Industry- A Case of Vodafone (Ghana).International Journal of Business and Management, 6 (5), 203-210.

Analysys Mason (2009). Market Study of the Telecommunications and ICT Sector in Botswana: From 1996 to the Future. BOCRA Unpublished Paper.

Bitner, M.J., Booms, B.H. and Tetreault, M.S. (1990). The Service Encounter: Diagnosing Favorable and Unfavorable Incidents. Journal of Marketing, 54, 71-84.

Cochran, W.G. (1977). Sampling Techniques, 3rd Edition. John Wiley \& Sons. New York. 
Czepiel, J.A. (1990). Service Encounters and Service Relationships: Implications for Research. Journal of Business Research, 20 (1).13-21.

Daniel, C.N. and Berinyuy, L.P. (2010), Using the SERVQUAL Model to Assess Service Quality and Customer Satisfaction: An Empirical Study of Grocery Stores in Umea. Unpublished Paper.

Dehghan, A. (2006). Relationship between Service Quality \& Customer Satisfaction: the Case of Customer Centric Group. Unpublished Paper.

Eshghi, A., Roy, S. K., and Ganguli, S. (2008). Service Quality and Customer Satisfaction: An Empirical Investigation in Indian Mobile Telecommunications Services. Marketing Management Journal, 18 (2), 119-144.

Joshi, S., Khurana, P. and Khurana, S. (2010). Service Quality in Telecom Sector- A Study of Telecom Service Providers of Chandigarh, Panchkula and Mohali.Sri Krishna International Research \& Educational Consortium, 1(1), 90-99.

Loke, S., Taiwo, A.A., Salim, H.M. and Downe, A.G. (2011).Service Quality and Customer Satisfaction in a Telecommunication Service Provider. International Conference on Financial Management and Economics Paper, vol.11.

Parasuraman, A., Zeithaml, V.A. and Berry, L.L. (1985).A Conceptual Model of Service Quality and its Implication.Journal of Marketing, 49, 41-50.

Parasuraman, A.and Zeithaml, V.A. (1988). SERVQUAL: A Multiple-Item Scale for Measuring Consumer Perceptions of Service Quality. Journal of Retailing, 1 (64), 12-40.

Saghier N. E. and Nathan, D. (2013). Service Quality Dimensions and Customers"Satisfactions of Banks in Egypt.International Business Research Conference Paper.

Sridhar,S.K. and Sridahr, V. (2009). Telecommunications Infrastructure and Economic Growth: Evidence from Developing Countries.

Statistics Botswana (2016). Selected Statistical Indicators. Gaborone, Statistics Botswana.

Szwarc,P. (2005). Researching Custonmer Satisfaction and Loyalty: How to Find Out What People Really Think. London: Kogan Page Publishers.

Vyas, S. and Kumaranayake, L. (2006). Constructing Socio-economic Status Indices: How to use Principal Components Analysis. Health Policy Plan (2006) 21 (6): 459-468. 


\section{APPENDICES}

Table A1: Descriptive Statistics for Service Quality by Mobile Operator

\begin{tabular}{|c|c|c|}
\hline Variable & Service Quality & Customer Expectations \\
\hline Access & 3.9 & 3.5 \\
\hline Ease of access to services & 4.0 & 3.5 \\
\hline Waiting period & 3.7 & 3.3 \\
\hline Convenience operating hours, location & 4.1 & 3.6 \\
\hline Assurance & 4.0 & 3.6 \\
\hline Value added services- music, internet & 3.9 & 3.6 \\
\hline Instils trust and confidence & 4.0 & 3.6 \\
\hline Communication & 4.2 & 3.7 \\
\hline Updates customers & 4.2 & 3.8 \\
\hline Response to queries & 4.1 & 3.6 \\
\hline Competence & 4.1 & 3.7 \\
\hline Employees' skills and knowledge & 4.1 & 3.7 \\
\hline Courtesy & 4.2 & 3.8 \\
\hline Employees polite and friendly & 4.2 & 3.8 \\
\hline Employees sincere and patient & 4.2 & 3.7 \\
\hline Credibility & 4.1 & 3.5 \\
\hline Trustworthiness and transparency & 4.1 & 3.5 \\
\hline Empathy & 4.0 & 3.5 \\
\hline Individualized attention & 3.9 & 3.5 \\
\hline Better understanding of customer needs & 4.0 & 3.5 \\
\hline Reliability & 4.0 & 3.6 \\
\hline Timely delivery of services & 4.0 & 3.6 \\
\hline Truthfulness, dependable and consistent & 3.9 & 3.6 \\
\hline
\end{tabular}




\begin{tabular}{lcc} 
Accurate Records & 4.2 & 3.6 \\
Responsiveness & 4.0 & 3.5 \\
Willingness to listen and assist & 4.1 & 3.7 \\
Promptly attend customers & 4.0 & 3.5 \\
Special care & 3.9 & 3.4 \\
Security & 4.1 & 3.7 \\
Confidentiality maintained & 4.1 & 3.7 \\
Understanding of Customer & 3.9 & 3.5 \\
Efforts to know customer needs & 3.9 & 3.5 \\
Tangibles & 3.8 & 3.6 \\
Attractive products & 3.8 & 3.5 \\
Appealing staff and offices & 3.7 & 3.6 \\
Up to date equipment & 3.9 & 3.7 \\
\hline
\end{tabular}

3.6

.5

3.7

3.5

3.4

3.7

3.7

3.5

.5

.6

.5

.6

7

Source: Author computed from survey data (2014)

Table A2: Descriptive Statistics for Customer Expectations

\begin{tabular}{lllll}
\hline Variable & Mascom & Orange & BeMobile & Total \\
\hline Access & 3.5 & 3.4 & 3.5 & 3.5 \\
Ease of access to services & 3.6 & 3.4 & 3.5 & 3.5 \\
Waiting period & 3.3 & 3.3 & 3.3 & 3.3 \\
Convenience- operating hours, location & 3.5 & 3.6 & 3.7 & 3.6 \\
Assurance & 3.6 & 3.7 & 3.7 & 3.6 \\
Value added services- music, internet & 3.6 & 3.7 & 3.6 & 3.6 \\
Instils trust and confidence & 3.6 & 3.6 & 3.8 & 3.6 \\
Communication & 3.6 & 3.8 & 3.8 & 3.7 \\
Updates customers & 3.7 & 3.9 & 3.8 & 3.8 \\
Response to queries & 3.5 & 3.7 & 3.7 & 3.6 \\
Competence & 3.6 & 3.7 & 3.6 & 3.7 \\
Employees' skills and knowledge & 3.6 & 3.7 & 3.6 & 3.7 \\
\hline
\end{tabular}




\begin{tabular}{|c|c|c|c|c|}
\hline Courtesy & 3.8 & 3.9 & 3.8 & 3.8 \\
\hline Employees polite and friendly & 3.8 & 3.9 & 3.7 & 3.8 \\
\hline Employees sincere and patient & 3.7 & 3.8 & 3.8 & 3.7 \\
\hline Credibility & 3.4 & 3.7 & 3.6 & 3.5 \\
\hline Trustworthiness and transparency & 3.4 & 3.7 & 3.6 & 3.5 \\
\hline Empathy & 3.5 & 3.5 & 3.6 & 3.5 \\
\hline Individualized attention & 3.4 & 3.5 & 3.6 & 3.5 \\
\hline Better understanding of customer needs & 3.5 & 3.5 & 3.5 & 3.5 \\
\hline Reliability & 3.5 & 3.6 & 3.7 & 3.6 \\
\hline Timely delivery of services & 3.5 & 3.6 & 3.6 & 3.6 \\
\hline Truthfulness, dependable and consistent & 3.5 & 3.6 & 3.7 & 3.6 \\
\hline Accurate Records & 3.6 & 3.6 & 3.8 & 3.6 \\
\hline Responsiveness & 3.5 & 3.6 & 3.6 & 3.5 \\
\hline Willingness to listen and assist & 3.6 & 3.8 & 3.7 & 3.7 \\
\hline Promptly attend customers & 3.5 & 3.6 & 3.6 & 3.5 \\
\hline Special care & 3.4 & 3.4 & 3.5 & 3.4 \\
\hline Security & 3.7 & 3.7 & 3.6 & 3.7 \\
\hline Confidentiality maintained & 3.7 & 3.7 & 3.6 & 3.7 \\
\hline Understanding of Customer & 3.5 & 3.5 & 3.4 & 3.5 \\
\hline Efforts to know customer needs & 3.5 & 3.5 & 3.4 & 3.5 \\
\hline Tangibles & 3.6 & 3.7 & 3.6 & 3.6 \\
\hline Attractive products & 3.5 & 3.6 & 3.6 & 3.5 \\
\hline Appealing staff and offices & 3.6 & 3.7 & 3.5 & 3.6 \\
\hline Up to date equipment & 3.7 & 3.7 & 3.6 & 3.7 \\
\hline
\end{tabular}

Source: Author computed from survey data (2014) 
Table A3: Variations on Customer Perceptions of Service Quality

Variable

Access

Ease of access to services

Waiting period

Convenience- operating hours, location

\section{Assurance}

Value added services- music, internet

0.967

0.893

0.850

0.813

Response to queries

\section{Competence}

Employees' skills and knowledge

\section{Courtesy}

Employees polite and friendly

Employees sincere and patient

\section{Credibility}

Trustworthiness and transparency

\section{Empathy}

Individualized attention

Better understanding of customer needs

0.635

0.010

0.027

0.728

0.625

0.015

0.026

0.754

\section{Reliability}

Timely delivery of services

Truthfulness, dependable and consistent

Accurate Records

Responsiveness
0.610

0.029

0.025

0.779

0.582

0.060

0.024

0.803

0.013

0.022

0.825

0.030

0.021

0.846

0.478

0.016

0.020

0.866

0.462

0.030

0.019

0.886 


\begin{tabular}{lcccr}
\hline Promptly attend customers & 0.412 & 0.039 & 0.017 & 0.921 \\
Special care & 0.373 & 0.010 & 0.016 & 0.936
\end{tabular}

\section{Security}

Confidentiality maintained

0.363

0.024

0.015

0.951

\section{Understanding of Customer}

Efforts to know customer needs

0.339

0.027

0.014

0.966

Tangibles

Attractive products

0.312

0.043

0.013

0.979

Appealing staff and offices

0.269

0.022

0.011

0.990

Up to date equipment

0.247

0.010

1.000

Source: Author computed from survey data (2014) 
Table A4: Variations on Customer Expectations

\begin{tabular}{|c|c|c|c|c|}
\hline Variable & Eigenvalue & Difference & Proportion & Cumulative \\
\hline \multicolumn{5}{|l|}{ Access } \\
\hline Ease of access to services & 10.728 & 9.431 & 0.447 & 0.447 \\
\hline Waiting period & 1.297 & 0.154 & 0.054 & 0.501 \\
\hline Convenience- operating hours, location & 1.143 & 0.120 & 0.048 & 0.549 \\
\hline \multicolumn{5}{|l|}{ Assurance } \\
\hline Value added services- music, internet & 1.023 & 0.172 & 0.043 & 0.591 \\
\hline Instils trust and confidence & 0.851 & 0.115 & 0.035 & 0.627 \\
\hline \multicolumn{5}{|l|}{ Communication } \\
\hline Updates customers & 0.735 & 0.040 & 0.031 & 0.657 \\
\hline Response to queries & 0.695 & 0.040 & 0.029 & 0.686 \\
\hline \multicolumn{5}{|l|}{ Competence } \\
\hline Employees' skills and knowledge & 0.655 & 0.027 & 0.027 & 0.714 \\
\hline \multicolumn{5}{|l|}{ Courtesy } \\
\hline Employees polite and friendly & 0.628 & 0.054 & 0.026 & 0.740 \\
\hline Employees sincere and patient & 0.575 & 0.028 & 0.024 & 0.764 \\
\hline \multicolumn{5}{|l|}{ Credibility } \\
\hline Trustworthiness and transparency & 0.546 & 0.011 & 0.023 & 0.787 \\
\hline \multicolumn{5}{|l|}{ Empathy } \\
\hline Individualized attention & 0.535 & 0.024 & 0.022 & 0.809 \\
\hline Better understanding of customer needs & 0.511 & 0.029 & 0.021 & 0.830 \\
\hline \multicolumn{5}{|l|}{ Reliability } \\
\hline Timely delivery of services & 0.483 & 0.008 & 0.020 & 0.850 \\
\hline Truthfulness, dependable and consistent & 0.475 & 0.034 & 0.020 & 0.870 \\
\hline Accurate Records & 0.441 & 0.026 & 0.018 & 0.888 \\
\hline \multicolumn{5}{|l|}{ Responsiveness } \\
\hline Willingness to listen and assist & 0.415 & 0.014 & 0.017 & 0.906 \\
\hline Promptly attend customers & 0.400 & 0.035 & 0.017 & 0.922 \\
\hline Special care & 0.366 & 0.025 & 0.015 & 0.938 \\
\hline \multicolumn{5}{|l|}{ Security } \\
\hline Confidentiality maintained & 0.341 & 0.011 & 0.014 & 0.952 \\
\hline \multicolumn{5}{|l|}{ Understanding of Customer } \\
\hline Efforts to know customer needs & 0.330 & 0.034 & 0.014 & 0.966 \\
\hline \multicolumn{5}{|l|}{ Tangibles } \\
\hline Attractive products & 0.295 & 0.023 & 0.012 & 0.978 \\
\hline Appealing staff and offices & 0.272 & 0.011 & 0.011 & 0.989 \\
\hline Up to date equipment & 0.261 & . & 0.011 & 1.000 \\
\hline
\end{tabular}

Source: Author computed from survey data (2014) 
Table A5: Principal Component Analysis of Customer Perceptions of Service Quality

\begin{tabular}{lllll}
\hline Variable & Component 1 & Component 2 & Component 3 & Unexplained \\
\hline Access & 0.2679 & $\mathbf{0 . 3 5 2 5}$ & $\mathbf{0 . 4 0 7 8}$ & 0.3057 \\
Assurance & 0.252 & $\mathbf{0 . 3 7 5 5}$ & $\mathbf{0 . 4 6 2 7}$ & 0.3077 \\
Communication & $\mathbf{0 . 2 9 1 6}$ & $\mathbf{0 . 4 0 1}$ & -0.101 & 0.2979 \\
Competence & 0.2834 & 0.2098 & $\mathbf{- 0 . 4 0 9 7}$ & 0.3272 \\
Courtesy & $\mathbf{0 . 2 9 8 7}$ & 0.0919 & $\mathbf{- 0 . 4 1 0 2}$ & 0.3045 \\
Credibility & $\mathbf{0 . 3 0 0 3}$ & 0.0643 & $\mathbf{- 0 . 3 1 5}$ & 0.352 \\
Empathy & $\mathbf{0 . 2 9 9 8}$ & -0.1497 & -0.2368 & 0.3675 \\
Reliability & $\mathbf{0 . 3 2 5 8}$ & -0.0114 & 0.1868 & 0.3005 \\
Responsive & $\mathbf{0 . 3 2 3 3}$ & -0.2459 & 0.0678 & 0.2746 \\
Security & 0.2776 & -0.2255 & 0.139 & 0.4479 \\
Understanding & 0.2598 & $\mathbf{- 0 . 5 4 6 8}$ & 0.0981 & 0.2771 \\
Tangibles & 0.2735 & -0.2907 & 0.2227 & 0.408 \\
\hline
\end{tabular}

Source: Author computed from survey data (2014)

Table A6: Principal Component Analysis of Customer Expectations of Service Quality

\begin{tabular}{llllll}
\hline Variable & Component 1 & Component 2 & Component 3 & Component 4 & Unexplained \\
\hline Access & 0.262 & $\mathbf{- 0 . 3 3 9}$ & $\mathbf{0 . 5 6 1}$ & 0.163 & 0.208 \\
Assurance & 0.297 & -0.109 & $\mathbf{0 . 4 2 0}$ & 0.110 & 0.265 \\
Communication & $\mathbf{0 . 3 0 7}$ & -0.120 & 0.295 & -0.007 & 0.289 \\
Competence & 0.256 & $\mathbf{0 . 6 7 4}$ & 0.064 & 0.233 & 0.156 \\
Courtesy & 0.289 & $\mathbf{0 . 4 9 6}$ & 0.047 & 0.095 & 0.231 \\
Credibility & 0.290 & 0.125 & 0.019 & $\mathbf{- 0 . 4 7 9}$ & 0.283 \\
Empathy & 0.290 & 0.077 & -0.170 & $\mathbf{- 0 . 3 4 4}$ & 0.336 \\
Reliability & $\mathbf{0 . 3 0 8}$ & -0.160 & -0.117 & -0.256 & 0.289 \\
Responsive & $\mathbf{0 . 3 2 9}$ & -0.033 & -0.115 & -0.040 & 0.259 \\
Security & 0.273 & -0.223 & -0.294 & -0.285 & 0.348 \\
Understanding & 0.268 & -0.196 & $\mathbf{- 0 . 4 6 2}$ & $\mathbf{0 . 4 7 9}$ & 0.197 \\
Tangibles & 0.287 & -0.151 & -0.243 & $\mathbf{0 . 4 1 6}$ & 0.279 \\
\hline
\end{tabular}

Source: Author computed from survey data (2014)

Table A6: Gap Scores of Service Quality Dimensions

\begin{tabular}{llll}
\hline Variable & P & E & Gap Score (P-E) \\
\hline Access & 3.93 & 3.46 & $\mathbf{0 . 4 7}$ \\
Assurance & 3.97 & 3.63 & 0.34 \\
Communication & 4.13 & 3.71 & 0.42 \\
Competence & 4.10 & 3.65 & $\mathbf{0 . 4 5}$ \\
Courtesy & 4.20 & 3.76 & $\mathbf{0 . 4 4}$ \\
Credibility & 4.07 & 3.54 & $\mathbf{0 . 5 3}$ \\
Empathy & 3.93 & 3.50 & 0.43 \\
Reliability & 3.96 & 3.59 & 0.37 \\
Responsive & 4.02 & 3.55 & $\mathbf{0 . 4 7}$ \\
Security & 4.08 & 3.68 & 0.40 \\
Understand & 3.89 & 3.51 & 0.38 \\
Tangibles & 3.79 & 3.62 & 0.17 \\
\hline
\end{tabular}

Source: Author computed from survey data (2014)

$\mathrm{P}=$ Perceptions, $\mathrm{E}=$ Expectations $(\mathrm{P}-\mathrm{E}=$ Service Quality Gap) 